\title{
AUtORIA DE UM tRABALHO CIENTíFICO
}

Andy Petroianu
Trabalho realizado no Departamento de Cirurgia Faculdade de Medicina da
Universidade Federal de Minas Gerais, Belo Horizonte, MG

RESUMO - Durante a elaboração de um trabalho científico, uma das dificuldades que por ventura podem ocorrer é a escolha dos participantes da pesquisa que devem compor a sua autoria. Situação ainda mais desagradável é a ordenação dos autores, de acordo com o mérito de cada um no trabalho.

OBJETIVO. Apresentar, de maneira justificada, uma proposta para a autoria do trabalho científico, mediante com a contribuição de cada membro da equipe de pesquisadores.

MÉTodo. Foi realizada uma avaliação da maneira de se propor a autoria científica nos principais centros de pesquisa do Brasil e na literatura pertinente, para a aquisição de subsídios com vista à presente proposta.
Resultados. São apresentados em ordem de entrada os principais autores do trabalho e aqueles que devem merecer apenas agradecimento. Propõe-se uma escala numérica, com vistas à participação de cada membro da equipe, para facilitar a inclusão de cada um dos autores.

Conclusöess. 0 mérito da autoria científica deve ser restrito aos participantes que tiveram uma colaboração intelectual ao trabaIho realizado, aliada a uma contribuição efetiva para a pesquisa ser realizada e concluída.

Unitermos: Trabalho científico. Pesquisa. Autoria. Mérito. Agradecimento.

\section{INTRODUÇÃO}

Apublicação científica tornou-se, sobretudo nos centros maiores, quase que obrigatória. A sentença "publish or perish" deixou de ser apenas um trocadilho de mau gosto para exprimir uma realidade. $\mathrm{O}$ conhecimento e a cultura pessoal despertam pouco interesse e raramente são valorizados, a menos que tragam proveito para a coletividade. Por conseguinte, a contribuição social é um dos fatores que mais influenciam a credibilidade e a importância do indivíduo.

O destaque profissional decorrente do trabalho científico pode ser percebido nos incentivos que os pesquisadores recebem, por meio de bolsas e outros auxilios financeiros, que evidenciam o interesse do governo e de várias instituições de fomento à pesquisa

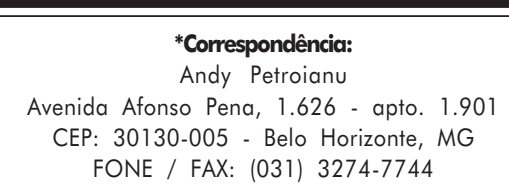

60 no desenvolvimento científico. No meio universitário, a cobrança por publicações éainda maior, a ponto de bloquear a ascensão daqueles que, mesmo sendo competentes e professores muito estimados, não apresentam atividade de pesquisa. Deve-se apontar ainda que o pesquisador é julgado pelo número de trabalhos publicados, sua qualidade e tipo de veículo publicitáriol-8.

Apesar de parecer secundário, é bom deixar claro que o egocentrismo, o dinheiro e o reconhecimento social têm papéis relevantes no estímulo à produção científica. $\mathrm{Na}$ carreira acadêmica, a vaidade representada pelo amor à fama é um dos fatores que mais impulsionam o progresso intelectual ${ }^{9-12}$.

Não existe mais dúvida quanto à importância da pesquisa. Entretanto, a distribuição da autoria, ao se confeccionar um manuscrito para publicação, não é uma tarefa fácil, diante dos diferentes valores, muitos dos quais subjetivos, que são levados em conta ao se estabelecer a seqüência dos nomes.

No presente capítulo, são discutidos tópicos relativos à autoria de um trabalho, bem como os aspectos mais importantes na ordenação de seus autores. São expostos alguns critérios no sentido de quantificar, de maneira objetiva, o mérito dos que trabaIham na pesquisa. Não será discutida a autoria de capítulos de livros ou de obras literárias, porfazerem parte da publicação didática ou cultural e seguirem outros critérios de avaliação.

\section{Disputa por autoria principal}

Quando alguma pesquisa tem a potencialidade de provocar um impacto maior na comunidade científica ouna sociedade, existe a tendência de seus responsáveis desejarem assumir a autoria principal do trabalho. Tendo em vista que as investigações são, geralmente, o resultado da contribuição de vários pesquisadores, é natural que cada membro da equipe considere a sua parte como sendo a mais importante. O impasse criado pode colocar em risco a própria publicação e comprometer o relacionamento dentro do grupo de pesquisa. 
Uma outra situação, mais comum e menos elegante, ocorre quando o colaborador sabe que sua contribuição foi menor, mas, diante da importância do trabalho, deseja sobrepor-se aos demais membros da equipe. Eventualmente, valendo-se de poder extrínseco à investigação e sem levar em conta normas éticas estabelecidas, tal indivíduo pode até obter sucesso com esse comportamento. A dimensão desse fato é identificada no cotidiano, não somente em grupo de pesquisadores mas em toda a sociedade. Os detentores do poder, por hierarquia, condição econômica, nível social, situação política, idade ou outra das muitas características da escala social, podem eventualmente admitir a igualdade ou pregar a justiça, desde que seus interesses individuais não estejam em jogo. Da mesma forma, no grupo de pesquisa, quem tiver ascensão sobre os demais poderá utilizar essa força para usurpar a autoria de um trabalho que seja de seu interesse. Lamentavelmente, há pouco recursos para evitar essa situação deplorável ${ }^{5-7,13}$.

\section{Critérios relativos à autoria científica}

A principal condição para ser incluído entre os autores é ter tido participação intelectual na elaboração, análise ou redação do trabalho $23,3,5,6,11,14-19$. Opesquisador deveainda estar envolvido com as etapas do estudo e participar das decisões importantes em sua condução. A criatividade voltada para o avanço científico merece autoria.

A falta de critérios universalmente aceitos quanto à autoria levou ao estabelecimento de diferentes convenções particularizadas a grupos ou setores científicos. Apenas para exemplificar, o primeiro autor pode ser o que teve a idéia, o que mais trabalhou, o orientador da investigação, o coordenador do grupo de pesquisa ou ainda o responsável pelo setor ou pela instituição onde foi desenvolvido o trabalho. Jáo último autor pode ser entendido como o que menos trabalhou, o orientador da investigação, o responsável

\begin{tabular}{|c|c|}
\hline \multicolumn{2}{|c|}{$\begin{array}{l}\text { Tabela I - Pontuação para autoria, de acordo com a participação } \\
\text { no trabalho }{ }^{2,5,6,15,1,6,18,19,2,22,23}\end{array}$} \\
\hline Participação & Pontos \\
\hline 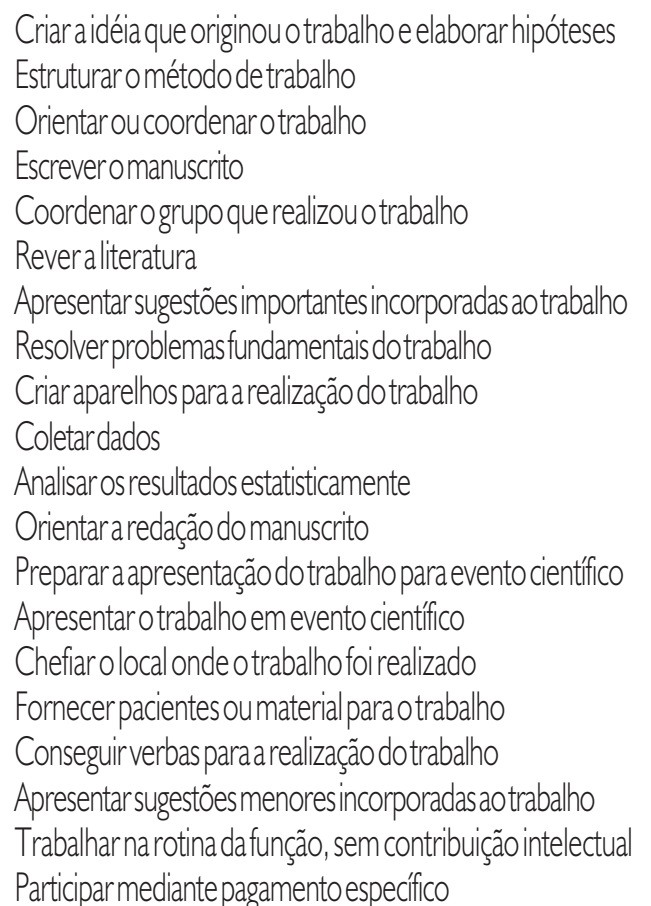 & $\begin{array}{l}6 \\
6 \\
5 \\
5 \\
4 \\
4 \\
4 \\
4 \\
3 \\
3 \\
3 \\
3 \\
3 \\
2 \\
2 \\
2 \\
2 \\
1 \\
1 \\
5\end{array}$ \\
\hline
\end{tabular}

Terãodireito a autoria os colaboradores quetiverem alcançado 7 pontos.

Asequiência dos autoresseráem ordem decrescentede pontuação.

pela instituição onde a pesquisafoidesenvolvida ou aquele que financiou o trabalho.

Diante dos conflitos que podem surgir devido à subjetividade implícita em grande parte desses critérios e falta de uniformidade entre eles, são discutidos, a seguir, alguns aspectos que merecem ser considerados ao se decidir pela autoria de um trabalho. A Tabela I traz o resumo desses tópicos e sugere uma pontuação para cada um deles.

\section{Criar a idéia que originou o trabalho e elaborar hipóteses}

Todo trabalho científico é oriundo de uma idéia, na maioria das vezes, buscando resposta para um problema. Surgem, então, hipóteses em torno dos fenômenos envolvidos com essa questão e propõem-se caminhos para sua provável solução. Em várias culturas e livros religiosos é citada uma sentença que contemporaneamente LéviStrauss lapidou como "Sábio não é o homem que fornece as verdadeiras respostas; é o que formula as verdadeiras perguntas". É incontestável que a qualidade do trabalho depende do valor da questão e de sua correta apresentação. Se a pergunta tiver sido bemfeita, ela pode inclusive conter o melhor caminho a ser seguido para se alcançar a resposta. Essa primeira etapa é certamente a base, sem a qual o trabalho jamais existiria. Portanto, aquele que teve a idéia e soube expor o problema merece receber a pontuação mais elevada $2,5,6,7,11,15,16,18,2,20$.

Não são raras as boas idéias que surgem até de pessoas leigas no campo de conhecimento em que teriam aplicabilidade. Conversas informais podem dar origem a temas 
que mereçam uma investigação científica maior. Cabe a quem elaborou a questão prosseguir no sentido de ela tomar o corpo de uma pesquisa. Se o dono da idéia não tiver competência paratal empreitada, ele poderá aliar-se a um grupo capaz de desenvolver o trabalho. Por outro lado, quando o dono da idéia não tiver o menor interesse ou empenho em levar adiante a investigação, ele pode até perder o direito à autoria.

\section{Estruturar o método de trabalho}

Asegunda etapa do trabalho, tão importante quanto a idéia, é sua estruturação para testar as hipóteses ou buscar a solução do problema. É preferível que o autor da idéia também seja capaz de estruturá-la, porém não há desdouro em procurar quem possa delinear a pesquisa deforma mais adequada. Diante da importância desta fase, o seu valor não pode ser inferior ao concedido a quem tevea idéía $25,6,15,16,18$,

\section{Orientar o trabalho}

Aorientação ou coordenação da pesquisa não deve ser entendida apenas como um relacionamento entre mestre e discípulo. Qualquer pesquisador ou equipe pode necessitar do auxilio de uma pessoa experiente no assunto, principalmente quando o estudo transcorrer em um campo científico ao qual os investigadores estiverem menos afeitos. Nesse caso, é aconselhável recorrer a um perito no tema considerado.

É evidente que a pontuação de quem apenas orienta não pode estar ao mesmo nível de quem teve a idéia ou delineou o trabalho. Todavia, como o orientador, por oficio, precisa participar de toda pesquisa, ele certamente alcançaráuma pontuação destacada dentre os autores $25,6,8,15$.

\section{Escrever o manuscrito}

Éindispensável que todo trabalho científico, depois de concluído, seja escrito e enviado para publicação. Não faz sentido realizar um estudo, independente de seu valor intrínseco, e não divulgá-lo. Todo artigo contribui de alguma maneira para o progresso científico e pode auxiliar a outros pesquisadores que trabalham na mesma área do conhecimento. Diante da importância capital do manuscrito, aquele que o produziu merece receber uma pontuação elevada ${ }^{5,15,16,18,19}$.

\section{Coordenar o grupo que realizou o trabalho}

A função de coordenar o grupo que está desenvolvendo a investigação é muito importante, pois é papel do líder aglutinar os membros da equipe e colocá-los nas funções que thes forem mais adequadas. $O$ entrosamento dos pesquisadores também depende, em grande parte, do coordenador. Eventuais divergências, tanto na parte específica da pesquisa quanto no inter-relacionamento pessoal, são muitas vezes contornadas com o auxilio do coordenador 2,6,8.

Pressupõe-se que essa pessoa seja um pesquisador mais experiente, capaz de enriquecer com seu conhecimento os trabalhos realizados pelo grupo. Portanto, mesmo não sendo indispensável ao trabalho em questão, ele faz jus a uma pontuação elevada.

\section{Rever a literatura}

A revisão bibliográfica devefazer parte de toda pesquisa, pelos subsídios que ela pode trazer à elaboração do projeto e para confrontar os resultados obtidos no trabalho com os previamente encontrados por outros autores. O estudo pode ser conduzido sem esta etapa e alcançar um bom êxito, porém corre-se o risco de cometer impropriedades que venham comprometê-lo e atéinvalidá-lo.

\section{Apresentar sugestões incorporadas ao trabalho}

Em todas as fases da pesquisa surgem oportunidades para sugestões comvista ao seu aperfeiçoamento ou para facilitar a sua condução. Todavia, algumas propostas colocam em risco o projeto inicial pelas profundas modificações a ele feitas. Portanto, diante de qualquer alteração na pesquisa, é indispensável meditar com cuidado sobre as suas repercussões e contar com a aprovação de toda a equipe antes de incorporá-la ${ }^{16}$.

Tendo havido uma considerável valorização do trabalho em decorrência de alguma sugestão, o seu autor merece receber uma pontuação elevada. Caso ele não pertença ao grupo, pode-se considerar o convite para sua inclusão, desde que haja aprovação unânime dos demais membros.

Por outro lado, se a incorporação de alguma nova proposta não tiver alterado consideravelmente a condução da pesquisa e influenciado em suas conclusões, o seu autor receberá apenas a pontuação mínima.

\section{Resolver problemas fundamentais do trabalho}

Não é incomum que, durante uma investigação, surjam impasses que coloquem em risco todo o estudo, por dificuldades em prossegui-la. Deve-se diferenciar a resolução de um problema oriundo do projeto original de propostas novas feitas a um trabalho que estava sendo conduzido sem impedimentos maiores. A resolução dos obstáculos é imprescindível, sob pena de se perder parte da importância do trabalho. Assim sendo, quem for capaz de solucionar um problema maior merece uma pontuação elevada e até eventual convite para ser incluído na equipe, caso não faça parte dela, desde que em concordância com todos os membros do grupo.

\section{Coletar dados}

A coleta dos dados é, muitas vezes, um trabalho monótono e demorado, porém raramente envolve algum tipo de contribuição intelectual. Dessaforma, ela não requer, necessariamente, uma formação específica dentro da área de conhecimento na qual a pesquisa está inserida e, mesmo diante da importância, do esforço e da demora em 
colher os dados, a pontuação de quem realizou esse trabalho é menor.

Tal situação pode gerar conflito com alguns colaboradores que, apenas porterem contribuído coma coleta de dados, podendo incluir até procedimentos cirúrgicos, julgamse no direito de serem autores da pesquisa e, eventualmente, almejam atéa condição de primeiro autor. $\mathrm{Na}$ realidade, deve-se ter muito claro que, de direito, somente aqueles que tiveram uma participação intelectual maior merecem se tornar autores. Os auxílios não intelectuais podem receber agradecimento. Para evitar disputas desagradáveis, essas informações têm que ser esclarecidas no início da tarefa $2,5,6,11,15,16,17,18$.

\section{Apresentação do trabalho em eventos científicos}

Muitos estudos, antes de serem publicados em revista, são apresentados como comunicações em eventos científicos. Tal procedimento éaconselhável, pois o debate que o trabalho pode gerar freqüentemente se acompanha de sugestões úteis ao enriquecimento da pesquisa e de seu manuscrito. Novos estudos na mesma linha também podem ser criados em conseqüência de tais discussões.

Quem esteve mais envolvido com o trabalho está mais apto a preparar uma boa apresentação e merece um crédito coerente com a tarefa. Contudo, há pesquisadores que, por motivos diversos, têm dificuldade em exibir seu trabalho em público. Nesse caso, um outro membro da equipe eaté uma pessoa externa a ela, se bem preparada, é capaz de expor o estudo realizado. É evidente que a pontuação de quem apenas apresentou deve ser menor,19.

Ao se submeter um trabalho para apresentação em evento médico-científico, cabe observar as normas determinadas por sua Comissão Cientíica. Na maioria das vezes, respeita-se a ordem de autoria determinada pelo grupo que submeteu o trabalho, even- tualmente solicitando-se sublinhar o nome do autor que irá apresentá-lo. Todavia, há casos em que as normas do evento definem o apresentador como o primeiro autor, fato que pode mudar a ordem estabelecida por direito de autoria.

Diante dessa situação, os pesquisadores podem solicitar à Comissão Científica para respeitar a ordem por direito dos autores. Não sendo atendidos, cabe atender as exigências do evento ou retirar o trabalho. Tendo como princípio que o mais importante é divulgar a investigação realizada, não há desdouro maior se os pesquisadores, de comum acordo, atenderem ao que thes é solicitado. Entretanto, na apresentação do trabalho, como tema-livre ou cartaz, deve constar a ordem correta dos autores. Ressalta-se ainda que a ordem dos autores com valor real é aquela apresentada no artigo publicado em revista. Poucos prestam atenção à ordem dos autores nos trabalhos publicados em anais de congressos.

\section{Chefiar o local onde o trabalho foi realizado}

O fato de ser chefe e ainda participar dos trabalhos é digno de uma pontuação específica. O mérito está no poder aglutinador da maioria dos chefes e no incentivo que a sua presença trabalhando é para os demais membros da equipe. Todavia, sua contribuição precisa ser também intelectual, pois, de outro modo, ele seria equiparado a um supertécnico, sem direito a autoria $2,6,11,15,21$.

\section{Fornecer pacientes ou material e conseguir verbas}

Em Medicina, muitas pesquisas são realizadas com doentes. Não é necessário que o médico avalie apenas seus próprios enfermos; ele poderá também investigar em prontuários de pacientes cadastrados em um serviço, hospital ou ainda solicitar de colegas a permissão para realizar o trabalho em doentes deles. Se forem seguidos, com todo rigor, os princípios éticos, normati- zados em diversos códigos, não deverá haver um empecilho maior a tal tipo de relacionamento entre o pesquisador, o paciente e seu médico.

Quando apenas um ou poucos médicos fornecerem seus doentes para o estudo, cada um desses profissionais terá direito integral aos pontos correspondentes a este tópico. Por outro lado, se for estudada alguma conduta propedêutica ou de tratamento criada ou adotada especificamente por um determinado profissional, ele passa a exercer o papel de quem criou aidéia utilizada no trabalho e receberá os pontos máximos, atribuídos no primeiro tópico desta secção do capítulo 2,13,15,21.

Para que um centro de pesquisa funcione, é aconselhável a divisão de trabaIho. $O$ atributo maior do pesquisador é a busca de soluções para problemas por meio de seu trabalho. Quanto mais elevado o nível da investigação, mais dispendiosa ela se torna. Cabe a quem pesquisa obter recursos para seu trabalho, já que são raros os que têm condição de financiar suas próprias pesquisas.

A fim de reduzir a perda de tempo dos pesquisadores, deveriam existir setores ou profissionais com a função de conseguir ou liberar verbas para a aquisição do material necessário à condução do trabalho. Usualmente, o chefe administrativo do setor exercetambémo papel de intermediário entre as fontes de fomento e o grupo de pesquisa. Todavia, por não haver um desempenho intelectual dirigido especificamente à investigação, os pontos concedidos por essa atividade, mesmo sendo indispensável, são poucos.

\section{Trabalhar na rotina da função}

Muitos trabalhos dependem da colaboração de diferentes profissionais, que, ao atuarem em suas funções, podem auxiliar na pesquisa. Entre os múltiplos exemplos, mencionam-se médicos, enfermeiras, diversos 
tipos de técnicos, secretárias e assim por diante. Cada um deles pode ter prestado uma grande colaboração ao estudo, entretanto o seu auxílio restringiu-se ao desempenho profissional de rotina. Na maioria das vezes, eles não têm um envolvimento maior com a pesquisa e sequer a conhecem. Seu trabalho restringe-se a cumprir a tarefa que thes foi solicitada. Portanto, a pontuação que thes é devidaémínima 2,15,16,17.

\section{Participar mediante pagamento específico}

Toda atividade científica pressupõe um ideal maior e não condiz com a remuneração financeira específica a ela. É evidente que os pesquisadores têm obrigações individuais, familiares e sociais mediadas pelo dinheiro e precisam ser pagos adequadamente para sua sobrevivência digna, bem como a de seus dependentes, dentro dos padrões pressupostos para seu nível social e intelectual. Contudo, o dinheiro recebido, sob forma de salário, ordenado ou bolsa, não deve ser por um trabalho específico, mas por sua atuação profissional e científica global ${ }^{2}$.

Portanto, de acordo com esse pressuposto, seria estranho algum membro da equipe exigir pagamento por sua contribuição à pesquisa na qual ele está envolvido e da qual fará parte como autor. Se, por outro lado, for importante para o bom andamento do trabalho a participação de um determinado profissional e ele colocar um preço por seu auxílio, o grupo poderá arcar com esse custo.

Diante da participação no trabalho, sob pagamento, o profissional receberá os pontos propostos na Tabela I, de acordo com a função realizada, porém deles serão subtraídos cinco pontos. A sua inclusão entre os autores dotrabalho dependerá, assim como paratodos os demais participantes, de sua pontuação final ter alcançado o valor proposto.

\section{Critérios para ordenar os autores}

Existem várias regras para se estabelecer a ordem dos autores de um determinado trabalho. Muitos grupos de pesquisa já têm estabelecidas algumas normas próprias, dentro das quais há uma perfeita harmonia. Não se deve alterar esse equilíbrio, sob pena de criar conflitos que coloquem em risco a própria integração da equipe.

O melhor é deixar bem claro e de comum acordo com todos os membros do grupo quais serão os princípios a serem seguidos para autoria, antes de iniciar o trabalho. As discordâncias têm que ser resolvidas no começo. Eventuais mudanças nas normas estabelecidas somente seriam moralmente aceitas se todos os membros da equipe concordassem espontaneamente com elas. Qualquer imposição é condenável, principalmente se vier de um superior que tenha poder sobre os demais.

Dentro do critério proposto neste capítulo, cada um dos membros da equipe irá receber os pontos correspondentes aos itens em que ele for incluído. Não há limite para o número de pesquisadores participantes nas etapas do trabalho. Assim, o membro do grupo irá receber a totalidade dos pontos de cada tópico no qual ele tiver mérito.

Após terem sido distribuídos todos os pontos, far-se-á a soma dos valores conferidos a cada membro da equipe. Se houver qualquer dúvida, ela deveráser discutida em grupo até chegar-se a um acordo. Diante de empate na pontuação, considera-se a seqüência dos itens da Tabela I. Aquele que tiver obtido pontos em um item mais alto ficará na frente dos demais. Caso não se possa atingir um senso comum, convida-se uma pessoa defora do grupo, de preferência que tenha ascensão sobre todos os membros da equipe e que possa estar em uma posição de imparcialidade, para atuar como juiz. O que é inadmissível é que, ao final da distribuição da autoria, surjam mágoas que possam interferir na integridade do grupo.

A seqüência dos autores será em ordem decrescente de pontuação até o mínimo de sete pontos. Valores inferiores denotam uma contribuição menos expressiva e inadequada para merecer autoria $2,6,16$

\section{AUTOR HONORÁRIO}

Finalizado o trabalho, os pesquisadores podem decidir conceder, de forma incorreta, autoria a uma pessoa alheia à pesquisa. O autor honorário é a forma mais comum de autoria inapropriada e que pode ser encontrada em até $25 \%$ dos artigos científicos. Entre as circunstâncias que levam a tal atitude estão:

- homenagear alguém importante na vida pessoal, profissional ou científica de um ou mais membros da equipe;

- homenagear alguém que, de alguma maneira, esteja ligado ao trabalho realizado, mesmo sem ter participação direta nele, como, por exemplo, o autor de uma determinada técnica;

- incluir entre os autores um nome de notoriedade científica, social ou ligado à revista na qual se deseja publicar o trabalho, com vista a um trânsito mais fácil para a publicação;

- retribuir a gentileza feita previamente por um determinado pesquisador em relação à equipe;

- permitira inclusão de um colega que esteja em dificuldade profissional, em decorrência de sua baixa produção científica.

O autor honorário tem que ser convidado e seu nome somente pode constar na autoria do trabalho após a sua aprovação explícita, de preferência por escrito. Uma vez incluído na publicação, esse autor será também responsável pelo conteúdo do trabalho. Portanto, ele somente deverá aceitar essa honra após analisar muito bem o manuscrito e certificar-se da verdade de todas as informações nele contidas. 


\section{Agradecimentos}

tópico de agradecimentos é o mais elegante do artigo publicado e mostra a boa índole dos autores, que souberam externar sua gratidão a quem os auxiliou. Em algumas situações, o agradecimento é obrigatório, como no caso das fontes que patrocinaram o trabalho e do local em que a pesquisa foi desenvolvida, caso ela não se tenha desenrolado no ambiente de trabalho próprio de seus autores. Nesta última condição, o nome do local já está incluído na apresentação dos autores. Caso a pesquisa seja realizada com doentes ou prontuários de instituição que não a de origem dos autores, torna-se obrigatória a menção desse local neste tópico 5,6,15-19,23,24.

A maior parte dos trabalhos trazem agradecimentos adequados, porém alguns autores incluem um número exagerado de nomes que tiveram participações mínimas, geralmente dentro de suas funções. Essa atitude, além de ser imprópria, deprecia os que de fato mereceram o reconhecimento.

No caso de uma tese ou monografia, é usual e de bom alvitre colocar nas páginas iniciais uma grande lista de agradecimentos. Nessa oportunidade, é muito pertinente que se estenda a lista de nomes até para quem deu uma contribuição menor, porém, necessariamente, ela tem que ser específica ao trabalho em questão. Todavia, ao transformar-se a tese em artigo de revista, essa lista deve ser restrita ao mínimo indispensável.

Não existe um princípio estabelecido para orientar os autores quanto aos nomes que devem ser incluídos neste tópico. Talvez possa ser utilizada a Tabela I e se conceda agradecimento a quem tiver obtido três a seis pontos, acrescentando-se ainda o nome das instituições e as fontes financiadoras.

\section{Considerações finais}

Observa-se, pelo presente capítulo, a complexidade que gira em torno da autoria de um trabalho científico. Este é um assunto muito delicado e que tem de ser cuidado com muita seriedade, pois envolve o nome e, por trás dele, todos os princípios individuais, como honra, credibilidade, respeito, interesses, ideais e assim por diante.

Julgamos importante reforçar que, para prevenir conflitos maiores, o grupo que se dispõe a realizar um trabalho científico deve, já de início, estabelecer, da forma mais objetiva possível, os critérios que serão adotados para distribuição da autoria.

Os tópicos abordados neste capítulo refletem os pontos de vista de seu autor com base na literatura, avaliação de vários centros de pesquisa e vivência científica pessoal. Cabe, portanto, ao leitor meditar sobre os valores apresentados e seguir a conduta que Ihe parecer mais correta e honesta.

\section{SUMMARY}

\section{AUTHORSHIP OF A SCIENTIFIC WORK}

BACKGROUND. Duringthe development ofa scientific research, one of the main difficulties is to choose the authors of the paper from all participants of the investigation. The organization of the authorship, based on the contribution of eachinvestigatorisstillmore complex.

OBIECTIVE. Topropose ajustified indicator for the authorship of a scientific paper.

METHOD. The author investigated the main research centers of Brazil in order to know their philosophy related to the authorship of a research. An assessment of the literature completed this study.

RESULTS. We present and justify the order of each investigator in the authorship or acknowledgment of the paper, based on his or her participation on the investigation

Conclusion. The investigator deserves to be included as an author of a scientific paper only if he or she has an intellectual participation in the work and also effectively contributed with the execution and accomplishment of the research. [Rev Assoc Med Bras 2002; 48(I): 60-5]

KEY WORDS: Scientific work. Research. Authorship. Acknowledgment.

\section{ReferÊNCIAS}

I. Petroianu A. Ética Moral e Deontologia Médicas Rio de Janeiro: Guanabara Koogan, 2000; p 197-204.

2. Digiusto E. Equity in authorship. Soc Sci Med 1994; 38: 55-8

3. Drenth JPH. Multiple authorship. JAMA 1998; 280: 219-21.

4. Fllangin A, Carey LA, Fontanarosa PB et al. Prevalence of articles with honorary authors and ghost authors in peer-reviewed medical journals. JAMA 1998; 280: 222-4.

5. Petroianu A. Elaboração do trabalho científico. Médico Moderno 1985; 4: 63-72.

6. Petroianu A. Autoria de um trabalho científico. Arq Med Hosp Fac Santa Casa São Paulo 1991; 11: 83-4.

7. Petroianu A. A pesquisa em Medicina. Medicina 1992; 25: 327-329.

8. Petroianu A. Considerações sobre a pósgraduação stricto sensu em Medicina. Rev Assoc Med Bras 1995; 41: 391-396.

9. Rennie D, Flanagin A, Glass RM. Conflicts of interest in the publication of science. JAMA 1991; 266: 266-7.

10. Rennie D, Yank V, Emanuel L. When authorship fails. JAMA 1997; 278: 579-85.

I I. Roland CG. Trends in authorship. Arch Intern Med 1970; 125: 77I-2.

12. Wilcox LJ. Authorship. JAMA 1998; 280: $216-7$.

13. Petroianu A. Aspectos éticos na pesquisa em animais. Acta Cir Bras 1996; 11: 157-164.

14. Brooten DA. Who's on first. Nursing Res 1986; 35: 259.

15. Hoen WP, Walvoort HC, Overbeke JPM. What are the factors determining authorship and the order of the author's names. JAMA 1998; 280: 217-8.

16. Huth EJ. Guidelines on authorship of medical papers. Ann Intern Med 1986; 104: 269-74.

17. Kassirer JP, Angell M. On authorship and acknowledgments. N Engl J Med 199I; 325: 1510-2.

18. King CR, McGuire DB, Longman AJ et al. Peer review, authorship, ethics, and conflict of interest. Image 29; 29: 163-7.

19. Petroianu A. Publicação do trabalho científico. Ciência e Cultura 1983; 37: 410-413.

20. Lévi-Strauss C. Antropologia estrutural 1970; Rio de Janeiro: Tempo Brasileiro.

21. Room R. Envolving standards for authorship. Addiction 1995; 90: 1321-2

22. Fye WB. Medical authorship. Ann Intern Med 1990; 113: 317-25.

23. Esser C. Rules needed on authorship. Nature 1997; 389: 903

24. Wenger NS, Korenman SG, Berk R et al. The ethics of scientific research. I Invest Med 1997; 45:371-380.

Artigo recebido: 15//2/2000

Aceito para publicação: | 9/06/200 | 